International Journal of Current Advanced Research

ISSN: O: 2319-6475, ISSN: P: 2319 - 6505, Impact Factor: SJIF: 5.995

Available Online at www.journalijcar.org

Volume 6; Issue 3; March 2017; Page No. 2726-2728

DOI: http://dx.doi.org/10.24327/ijcar.2017.2728.0090

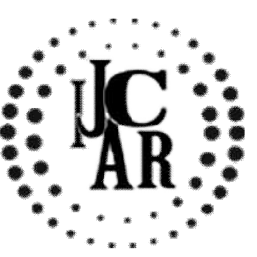

Research Article

\title{
EFFECTIVENESS OF MEDICATED SHAMPOO AGAINST HAIR LOSS
}

\author{
Harini.K and Lakshmi.T
}

Department of Pharmacology, Saveetha Dental College and Hospitals, Chennai, India

\begin{tabular}{|c|c|}
\hline 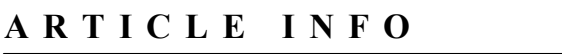 & A B S T R A C T \\
\hline Article History: & \multirow{7}{*}{$\begin{array}{l}\text { Dandruff is a chronic and most common scalp condition presented in the form of white } \\
\text { flakes which appear on the scalp. These flakes from the superficial skin layer made of dead } \\
\text { skin cells result in itching. Vigorous scratching ultimately leads to hair fall. It could also be } \\
\text { caused by eczema, psoriasis, or, very commonly, an overgrowth of a yeastlike fungus } \\
\text { called malassezia. Drugstore remedies might include shampoos with zinc pyrithione, which } \\
\text { targets fungus and bacteria; ketoconazole, which also fights fungus; coal tar and selenium } \\
\text { sulfide, which slow the growth and die-off of skin cells on your scalp; and salicylic acid, } \\
\text { which loosens flakes so they can be washed away. Hence, the main objective of this study } \\
\text { is to evaluate the effectiveness of the medicated shampoo against hairloss. }\end{array}$} \\
\hline Received $20^{\text {th }}$ December, 2016 & \\
\hline Received in revised form $24^{\text {th }}$ January, 2017 & \\
\hline Accepted $6^{\text {th }}$ February, 2017 & \\
\hline Published online $28^{\text {th }}$ March, 2017 & \\
\hline Key words: & \\
\hline Oil, Hair loss, herbal shampoo, $\mathrm{m}$ & \\
\hline
\end{tabular}

shampoo, home remedies.

Copyright $\subseteq 2017$ Harini.K and Lakshmi.T. This is an open access article distributed under the Creative Commons Attribution License, which permits unrestricted use, distribution, and reproduction in any medium, provided the original work is properly cited.

\section{INTRODUCTION}

Hair is a primary characteristic of mammals. Hair is an important component of the body derived from ectoderm of skin. It is a protective appendage on the body and considered necessary structure of the integument along with sebaceous glands, sweat glands and nails (1). Everyone nowadays is realising that continuous exposure of harmful chemicals to the hair causes hair damage (2). Two drugs have been approved by the Food and Drug Administration for the treatment of hair loss due to androgenetic alopecia: topical minoxidil solution and oral finasteride. (3) Major causes of hair loss are dihydrotestosterone (derivative of testosterone, a male hormone), poor blood flow, sebum emotional strains, stresses and nervous disorders, ageing, infections, hormonal imbalance, polluted environment, toxic substances, injury and impairment, radiation (4). Shampoos are not only scalp cleaners, but indubitably act as preventing the hair shaft damage. Many scalp diseases are also treated by active ingredients that are added to the shampoo's formulations (5). The aim of this study is to evaluate the effectiveness of medicated shampoo against hair loss.

\section{MATERIALS AND METHODS}

A questionnaire consisting of 16 questions which evaluates the effectiveness of shampoo and oil usage were made. It is distributed to randomly chosen 100 people. Questions include frequency of washing hair, type of shampoo used, number of hairs that fall out each day, type and frequency of oil usage. Responses were recorded and analysed.

*Corresponding author: Harini.K

Department of Pharmacology, Saveetha Dental College and Hospitals, Chennai, India

\section{RESULTS AND DISCUSSION}

In the results, $31 \%$ of people reported with no hair problems. $42 \%$ of people are washing their hair once every two or three days, $29 \%$ of people are washing once a day, $18 \%$ of people are washing every week, $11 \%$ of people are washing every other day. $37 \%$ of people have used medicated shampoo. $64.9 \%$ of people felt that the use of medicated shampoo controls the hair loss. $38 \%$ of people have used home remedies. $73 \%$ of people felt that the use of home remedies controlled hair loss. 50\% of people prefer Acacia (Shikakai).21.1\% of people prefer aloe vera.23.7\% of people prefer hibiscus. $5.3 \%$ of people prefer henna. $35 \%$ of people have used herbal shampoo. $77.1 \%$ of people felt that the use of herbal shampoo controls hair loss. $41 \%$ of people are unsure about the number of hairs that fall out each day.18\% of people reported that more than 100 hairs fall out each day.

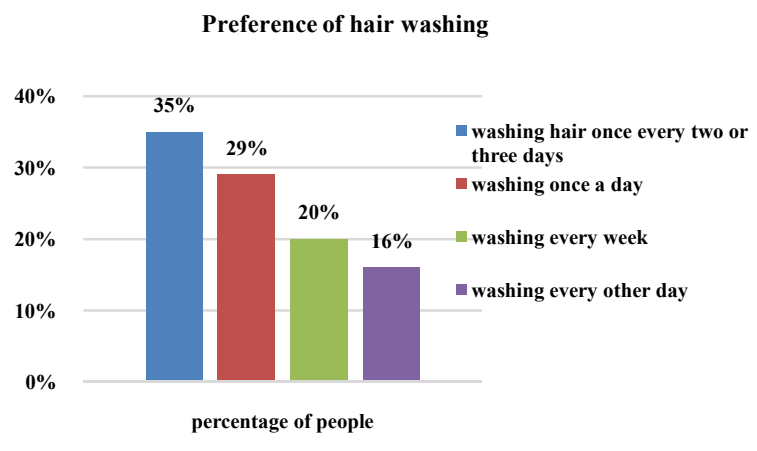



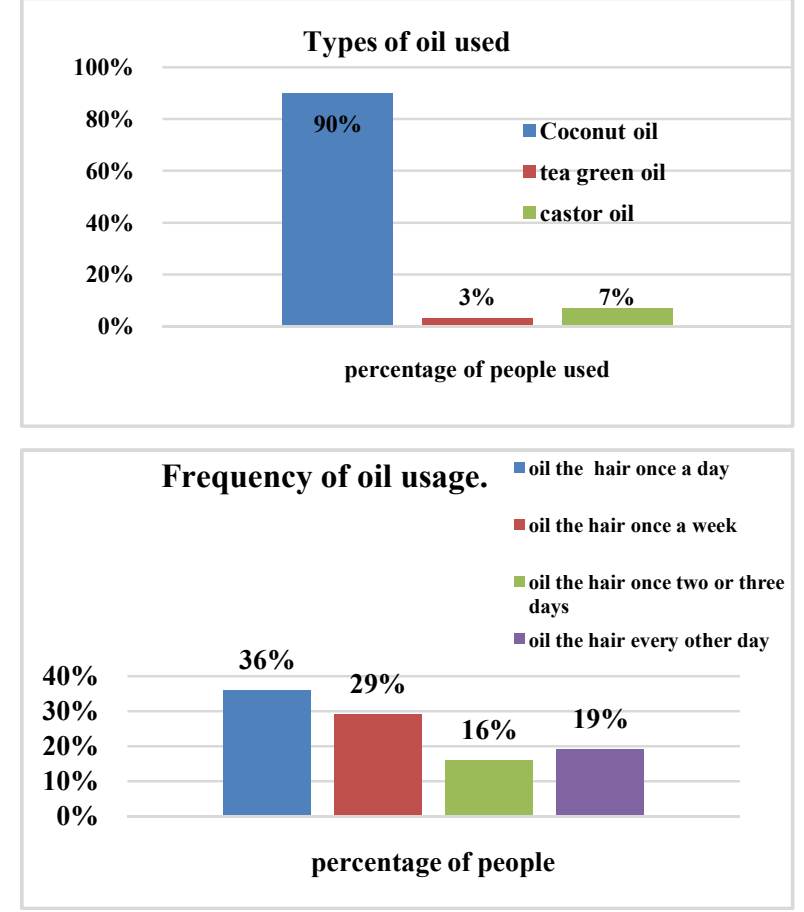

\begin{tabular}{ccccc}
\hline & \multicolumn{2}{c}{$\begin{array}{c}\text { Percentage of } \\
\text { people used }\end{array}$} & \multicolumn{2}{c}{$\begin{array}{c}\text { Percentage of people felt } \\
\text { that the usage controlled } \\
\text { hair loss }\end{array}$} \\
\hline & yes & No & yes & No \\
\hline $\begin{array}{c}\text { Medicated } \\
\text { shampoo }\end{array}$ & $37 \%$ & $63 \%$ & $64.9 \%$ & $35.1 \%$ \\
Home remedies & $38 \%$ & $62 \%$ & $73.7 \%$ & $26.3 \%$ \\
Herbal shampoo & $35 \%$ & $65 \%$ & $77.1 \%$ & $22.9 \%$ \\
\hline
\end{tabular}

$41 \%$ of people reported that less than 100 hairs fall out each day. $36 \%$ of people have dandruff. $55.6 \%$ of people have dry skin related dandruff. $16.7 \%$ of people have oily type dandruff. $27 \%$ of people have fungal dandruff. $61 \%$ of people have dry hair. $86 \%$ of people use coconut oil. $5 \%$ of people use tea green oil. $9 \%$ of people use castor oil.35\% of people oil their hair once a day. $29 \%$ of people oil their hair once a week. $19 \%$ of people oil their hair once every two or three days. $17 \%$ of people oil their hair every other day.

In the results,

$31 \%$ of people reported with no hair problems.

$42 \%$ of people are washing their hair once every two or three days, $29 \%$ of people are washing once a day, $18 \%$ of people are washing every week, $11 \%$ of people are washing every other day. $37 \%$ of people have used medicated shampoo. $64.9 \%$ of people felt that the use of medicated shampoo controls the hair loss. $38 \%$ of people have used home remedies. $73 \%$ of people felt that the use of home remedies controlled hair loss. $50 \%$ of people prefer Acacia (Shikakai).21.1\% of people prefer aloe vera.23.7\% of people prefer hibiscus.5.3\% of people prefer henna. 35\%of people have used herbal shampoo.77.1\% of people felt that the use of herbal shampoo controls hair loss. $41 \%$ of people are unsure about the number of hairs that fall out each day. $18 \%$ of people reported that more than 100 hairs fall out each day. $41 \%$ of people reported that less than 100 hairs fall out each day.36\% of people have dandruff.55.6\% of people have dry skin related dandruff. $16.7 \%$ of people have oily type dandruff. $27 \%$ of people have fungal dandruff.61\% of people have dry hair. $86 \%$ of people use coconut oil. $5 \%$ of people use tea green oil.
$9 \%$ of people use castor oil. $35 \%$ of people oil their hair once a day. $29 \%$ of people oil their hair once a week. $19 \%$ of people oil their hair once every two or three days. $17 \%$ of people oil their hair every other day.

By analysing the data, out of $31 \%$ of people with no hair problem, $35 \%$ of people are washing their hair once every two or three days, $29 \%$ of people are washing once a day, $20 \%$ are washing every week, $16 \%$ of people are washing every other day. $90 \%$ of people use coconut oil, $3 \%$ of people use tea green oil, $7 \%$ of people use castor oil. $36 \%$ of people oil their hair once a day, $29 \%$ of people oil their hair once a week, $16 \%$ of people oil their hair once two or three days, $19 \%$ of people oil their hair every other day. By interpreting the data, it can be concluded that people who prefer to wash their hair once every two or three days, prefer coconut oil and oil their hair once a day will experience no hair problem.

Coconut oil treats damaged hair by penetrating into hair fibres and acting as a moisturizer. When coconut oil is used as a prewash and post-wash grooming product, it can reduce protein loss for both damaged and healthy hair. The lauric acid present in coconut oil has an affinity for hair proteins and because of its low molecular weight it can penetrate the hair fibres and prevent hair damage (6). Coconut oil also hasa protective effect on chemically treated hair and hair treated with boiling water (7).

$77.1 \%$ of people felt that the use of herbal shampoo controls the hair loss. Hence it can be concluded that the use of herbal shampoo controls hair loss.

\section{CONCLUSION}

Hair fall has become a major problem affecting the day to day activities. Frequent washing, blow drying, and dyeing your hair doesn't destroy hair follicles or slow hair growth. However, these activities might make your current hair more brittle and fragile. But even if you damage a hair to the point of falling out, the same hair follicle will produce a new one to take its place. Now a days, both men and women take more care about hair problems. However, the significant use of medicated shampoo is not well known among many individuals. Hence the usage of medicated shampoo has become less. The choice of use of herbal shampoo, coconut oil, washing hair once every two or three days, oiling the hair once a day will prevent hair loss.

\section{References}

1. Ranjan C. Rawal, Palak Gandhi, T.B.Singh, K. H. H. V. S. S. Narasimha Murthy. Clinical evaluation of hairbac tablet and oil in the management of diffuse hair loss: an open clinical study. Int. J. Res. Ayurdha Pharm.4(4), Jul-Aug 2013.

2. Snehal More, Jaya Gade, Jyotsna Waghmare. Microencapsulation of fenugreek seeds oil and curry leaves oil using simple coacervation and its application in shampoo. Asian Journal of Science and Technology .Vol.06, Issue, 10, pp. 1902-1906, October, 2015.

3. Ralf Paus, George Cotsarelis. The biology of hair follicles. New England Journal of Medicine. September 1999

4. Kashyap Rakesh, Dr. Shukla Karunakar, Dr. Mahajan SC, Mr. Sharma Alok. Formulation and evaluation of 
hair oil for hair loss disorders. Journal of Medicinal Plants Studies 2016; 4(3): 13-17

5. Maria Fernanda Reis Gavazzoni Dias. Hair Cosmetics: An Overview. International Journal of Trichology, 2015 Jan-Mar; 7(1): 2-15.

6. Rele AS, Mohile RB. Effect of mineral oil, sunflower oil, and coconut oil on prevention of hair damage. $J$ Cosmet Sci. 2003 Mar-Apr; 54(2):175-92.

7. Aarti S.Rele, R.B.Mohile. Effect of coconut oil on prevention of hair damage.j. CosmeSt.ci.,50, 327-339 (November/December1999)
8. Nagaraj G, Sukumar A, Lokesh K S.Does hair care activities influence hair care elements. International journal of pharmacology and therapeutics. ISSN 2249 - 6467.

9. Jain PK, Dass DJ. Evaluating hair growth potential of some traditional herbs. Asian journal of pharmaceutical and clinical research.vol 8, issue 6, 2015.

10. Shah Bhairavi Suresh, Pimpalkhare Aditi Yashvant.To study etiological factors of premature graying of hairs. International Ayurvedic Medical Journal. ISSN: 2320 5091.

11. T.Lakshmi, R.Rajendran, V.Krishnan. Perspectives of oil pulling therapy in dental practice. Dental hypothesis 4(4), 131, 2013.

12. R.Rajeshwari, T.Lakshmi. Dental hypothesis. Lemon grass oil for improvement of oral health. Dental hypothesis 4(4), 115, 2013.

Please cite this article in press as:

Harini.K and Lakshmi.T (2017), Effectiveness of Medicated Shampoo Against Hair Loss, International Journal of Current Advanced Research, 6(3), pp. 2726-2728.

http://dx.doi.org/10.24327/ijcar.2017. 2728.0090 